\title{
Design and Development of Carborne Survey Equipment
}

\author{
Syarbaini $^{1^{*}}$, Bunawas ${ }^{1}$ and I.P. Susila ${ }^{2}$ \\ ${ }^{I}$ Center for Radiation Safety Technology and Metrology, National Nuclear Energy Agency, \\ Jl. Lebakbulus Raya No.49, Jakarta 12440, Indonesia \\ ${ }^{2}$ Center for Nuclear Facilities and Engineering, National Nuclear Energy Agency, \\ Kawasan Puspiptek Serpong, Tangerang Selatan 15310, Indonesia
}

\section{ARTICLE INFO}

\section{Article history:}

Received 04 October 2014

Received in revised form 16 March 2015

Accepted 23 March 2015

Keywords:

Nuclear emergency

Radiological emergency

Carborne survey

Real-time measurement

\begin{abstract}
A B S T R A C T
In most nuclear and radiological emergencies involving the release of radioactive materials to environment, it is important that data on the geographic distribution of potentially hazardous radioactive materials be quickly presented to the authorities. The mobile radiation detection system makes it possible to measure radioactive materials in the environment at random places because of its easy mobility from place to place. The purpose of the work is to develop a mobile radiation detection system to measure gamma exposure rate, radioactive material on the ground and airborne radioactive particulate in the environment quickly. In this work, we have developed a carborne survey equipment system consisting of three gamma ray detectors, one airbome radioactive particulate sampler, a GPS (Global Positioning System), meteorological sensors, a data acquisition system and an operation software. Performance of the carborne survey equipment has been successfully demonstrated to measure iodine and argon release from medical isotope production facility on Serpong in western Java, Indonesia.
\end{abstract}

\section{INTRODUCTION}

Prevention and preparedness for response to nuclear and radiological emergencies involves identification of various accident and emergency scenario which can lead to radiological consequences to public. The nature of the accident and its radiological impact must be identified rapidly and accurately for managing the emergency and its potential consequences for public health and the environment. The external dose rate and nuclide specific activity concentrations in air must be determined to evaluate the risk to the people. Airborne radioactive particulate can be analyzed quantitatively using gamma-ray spectrometry. This is a sensitive method to evaluate the radionuclide-specific concentrations in air [1-4].

\footnotetext{
* Corresponding author.

E-mail address: sarbaini@batan.go.id

DOI: http://dx.doi.org/10.17146/aij.2015.383
}

Nuclear and radiological emergencies causing release of radioactivity in significant quantities may lead to large area contamination. Therefore rapid and accurate measurements is important to determine radionuclides to evaluate the risk to the people. The authorities must have reliable real-time information for quickly planning the appropriate emergency response so that any civil defence countermeasures can be justified and realised. Air dose rate maps and assessing the radiological risk to the public must be taken before making plans for minimizing exposure to the public. The carborne survey equipment is known as the effective technique for characterizing the impact of radioactive contamination on the environment in a post nuclear accident scenario [2-6].

Nuclear and radiological radiation emergency preparedness is very much essential for all nuclear facilities to reduce the consequences, if at all any major release occurs from these facilities. The radiological impact following any nuclear 
accident depends on many factors including quantity and quality of radioactivity released, meteorological conditions during the release, topography around the site, elevation of release etc. In case of major releases to the environment, prompt and effective implementation of countermeasures can reduce the radiological consequences to the public. Hence, development of carborne survey equipment for response to such emergencies are very essential. The early detection of accidental releases, quick assessment and prediction of radiological impact, capability of implementing effective countermeasures etc are components of nuclear emergency response. The facility of environmental dose rate monitoring system using mobile equipment is essential for an effective response to any major nuclear emergency. Geographical distribution of radioactive contamination in most nuclear emergencies is essential to be presented quickly to the authorities for protecting public health and safety [7-11].

Beside that in nuclear radiation emergency, air dose rate maps are quite important to help take measures to deal with the incident, such as assessing the radiological dose to the public, making plans for minimizing exposure to the public, or establishing procedures for environmental reclamation. The carborne-ray survey technique is known to be one of the effective methods to make air dose-rate maps. Such monitoring cars tend to be multifunctional instrument. Real-time measurements and the fast analysis of the results are of crucial importance in a radiological emergency. The mobile radiation detection system makes it possible to inspect confidentially a suspicious vehicle at random places because of its easy mobility from place to place. Thus, this mobile radiation detection system can make contribution to enhancing the national ability to prevent and detect the illicit trafficking etc $[12,13]$.

The objective of the present work is to develop of a carborne survey equipment that is integrated, real-time and mobile system. Then the equipment was performed to monitor release of radionucldes gaseoes from the medical isotope production facility on Serpong in western Java, Indonesia.

\section{EXPERIMENTAL METHODS}

\section{Design of carborne survey equipment}

Carborne Survey equipment was designed on a mobile vehicle containing the main components such as the radiation measuring detectors, GPS
(Global Positioning System), a data acquisition system (DAQS), an operation software, and data processing unit (personal computer). In addition to the main components are aiborne radioactive particulate sampler for radioactive iodine and dust monitor together with wind speed, temperauture and humidity measuring instruments. Outline of the systematic diagram of the carborne survey equipment is shown as Fig. 1.

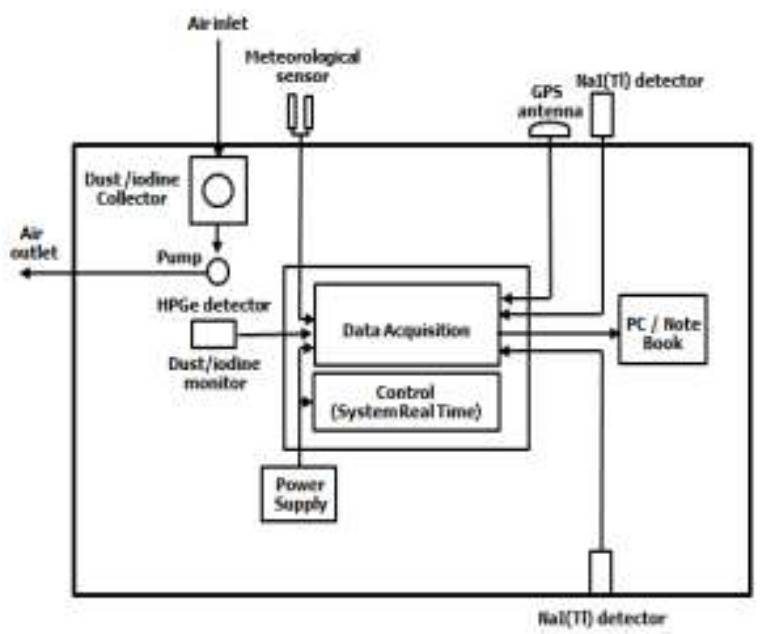

Fig. 1. Schematic diagram of the Carborne Survey Equipment.

\section{Construction of carborne survey equipment}

The mechanical installation and placement of the radiation detector equipment are very important in the construction of mobile detection systems. Radiation detectors must be placed and positioned so the most sensitive area of the detector window is pointed in the right direction. The general construction of a carborne survey equipment system is shown in Fig. 2. The system has two $\mathrm{NaI}(\mathrm{Tl})$ scintillation detectors which are mounted inside and outside the vehicle (opposite roof and floor). The first detector is mounted on a floor with the crystal endcap facing down toward the ground. The second detector is mounted on the roof directly facing upwards. Each of detector is surrounded with lead $(\mathrm{Pb})$ shields of $5.1 \mathrm{~cm}$ as shown in Fig. 3. This type of configuration enables good detection and localization of radiation sources. The third detector is a HPGe detector that is placed inside a mobile vehicle for measuring the radioactive dust and iodine in filter paper and charcoal cartridge respectively. The detector is intended for examining the filter paper on which dust has been collected by air sampler. Sharing the sampler with the dust monitor, it is so designed as to collect dust via a charcoal cartridge having $99 \%$ of collecting efficiency. 


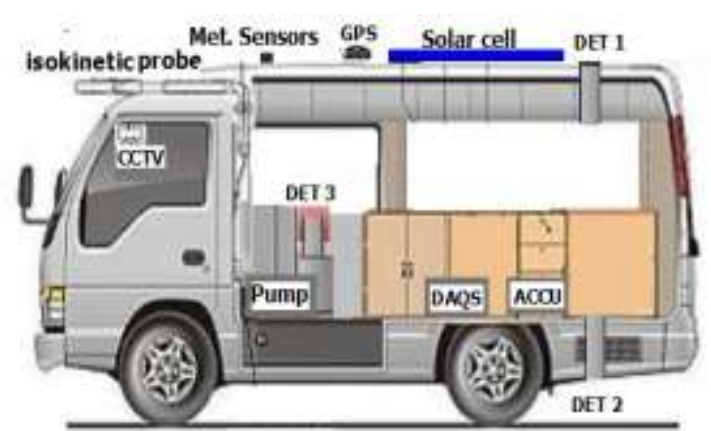

Fig. 2. Construction of a carborne survey equipment.

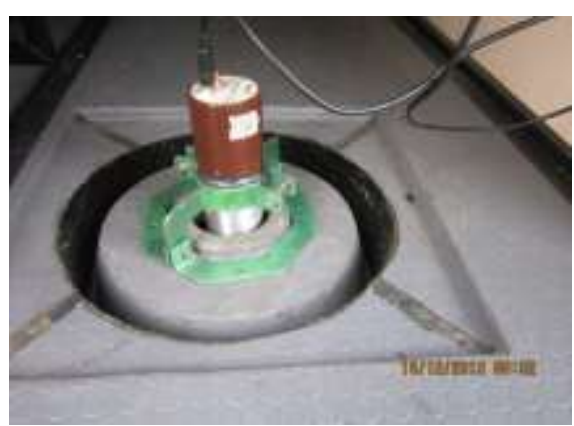

(a)

$\mathrm{NaI}(\mathrm{Tl})$ detector at the vehicle floor

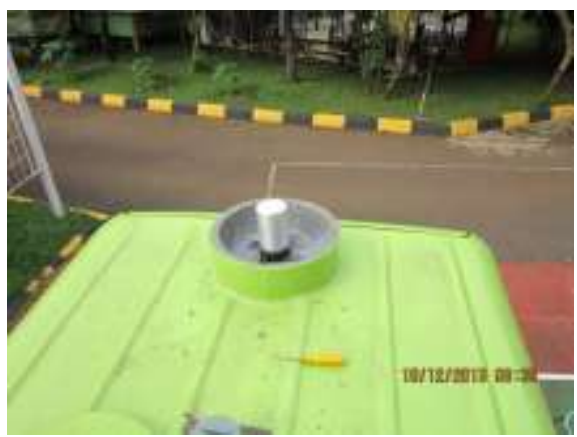

(b)

$\mathrm{NaI}(\mathrm{Tl})$ detector at the vehicle roof

Fig. 3. $\mathrm{NaI}(\mathrm{Tl})$ detector of carborne survey equipment (a) (b).

The auxiliary instruments such as GPS, meteorological sensors are located on the roof of mobile vehicle. The GPS is located at a place on the roof from which the satellite view would be maximum and the meteorological sensors was installed on the roof in order to measure the velocity and the direction of the wind, temperature and humidity. Airborne radioactive particulate is sampled using a filter or a charcoal cartridge. The radionuclide concentration is measured by using gamma-ray spectrometry with HPGe detector. This method was introduced by T. Honkamaa, et al. [1] as a quantitative and sensitive method to evaluate the radionuclide-specific concentrations in air. Thus, the whole sampling procedure can be carried out when the car is moving. The filter can be changed inside the vehicle.
The carborne survey is equipped with one fixed air samplers. The system is equipped with adjustable air flow, with possibility of stepwise adjustment; and filter holder cassettes to facilitate easy sample handling. This allows making measurements of samples and filters directly at the sampling point. While the vehicle is moving, the operator can change the filter and put the sample into the lead shield for counting. The system has also a forward looking surveillance camera with digital image storage to the laptop. All the detectors/sensors are attached to the DAQS (Data acquisition system), and the DAQS is connected to a laptop computer.

\section{Performance test of carborne survey equipment}

In order to conduct performance test, the carborne survey equipment system was used to monitor the discharge of radioactive gases from the medical isotope production facility in Serpong in west Java, Indonesia. This facilty serves 16 hospitals in Indonesia and also exports its production to medical centres in several countries. For this purpose, the vehicle roof mounted detector was applied. Computer codes using a Monte-Carlo approach methodology was used for calculating that detector efficiency calibration. The Monte Carlo technique is a widely used simulation tool for radiation transport, mainly in situations where measurements are inconvenient or impracticable. The Monte Carlo methods make it possible to calculate the response function for detectors with good accurate results [14,15]. Monte Carlo models of the detectors used in this work were constructed using the MCNP5 code $[16,17]$. To ensure that the model was accurate, a standard point sources traceable to the Amersham were measured across the front face of the detector.

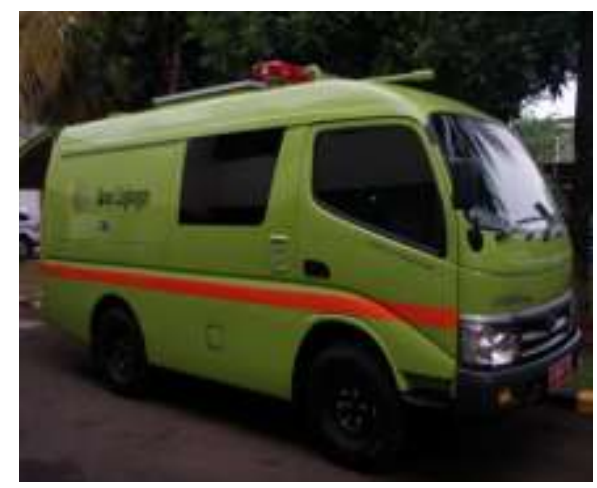

Fig. 4. Survey equipment. 


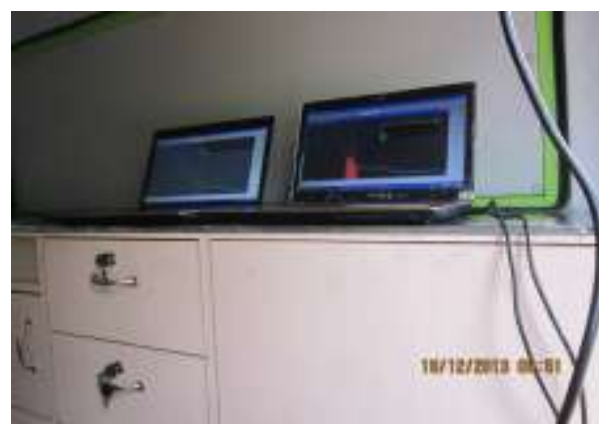

Fig. 5. Real-time measurement.

\section{RESULTS AND DISCUSSION}

Simulation of detector calibration using the Monte Carlo method was performed with input parameters such as detector characterization and geometry, the definition of the radiation source and pulse count model. The models were initially based entirely on detector dimensions supplied by the manufacturer. A visual rendering of the detector model is given in Fig. 6.

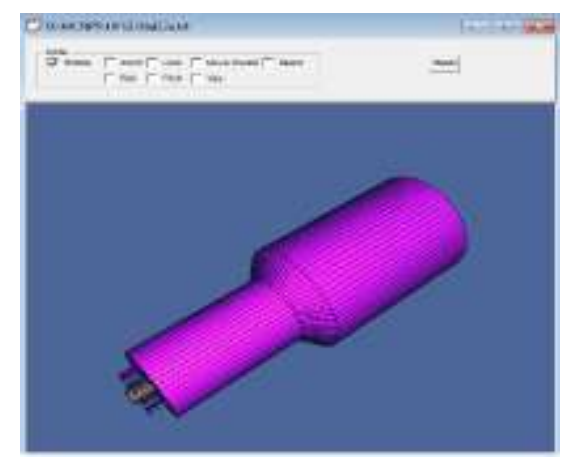

Fig. 6. MCNP Visual representation of $\mathrm{NaI}(\mathrm{Tl})$ detector.

In this work the 3"x3" $\mathrm{NaI}(\mathrm{Tl})$ detector and lead shield were also modeled using the MCNP5. A three dimensional visual representation of the model is shown in Fig. 7.

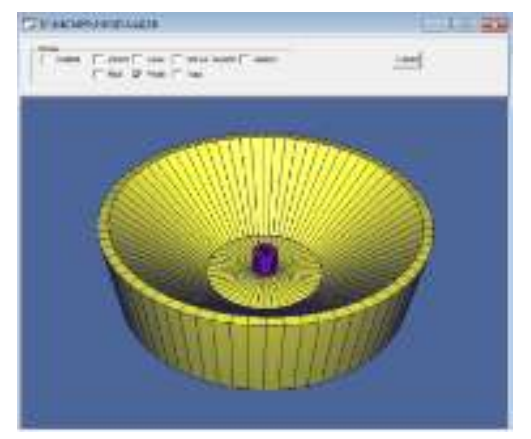

Fig. 7. MCNP Visual representation of $\mathrm{NaI}(\mathrm{Tl})$ detector and lead shield.

The radiation source was assumed as a spherical source where a dose point is placed inside the sphere. In this work the performance test of the carborne survey equipment is used to monitor release of radioactive gases from medical isotope production stack. Therefore this geometry could be assumed that the source is a cloud or plume of air containing radioactive elements in the form of gasses or particles and the dose point is at the ground surface [18-20]. The radiation dose to a person submerged in a radioactive plume could be estimated using calculations based on this geometry. The cloud of radiation such as a radioactive plume can be simulated from measurements with radioactive sources on the surface of a sphere as can be seen in Fig. 8 .

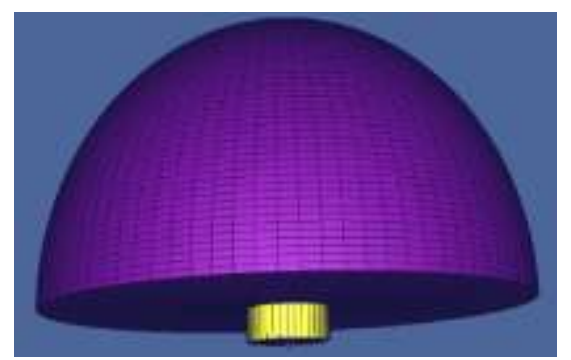

Fig. 8. MCNP Visual representation of $\mathrm{NaI}(\mathrm{Tl})$ detector with radiation source $\mathrm{R}=3 \mathrm{~m}$.

Based on the modelled detector, radiation source and pulse count, the calibration efficiency of the vehicle roof mounted detector was calculated as shown in Table 1. In the MCNP simulation output accompanied by error, which is defined to be one estimated standard deviation of the mean divided by the estimated mean. The efficiency output is reliable if the error values is less than $5 \%$ [16].

Table 1. MCNP5 simulation for efficiency of several nuclides

\begin{tabular}{lccc}
\hline Nuclide & Energy $(\mathrm{MeV})$ & Efficiency & Error \\
\hline Xe-133 & 0.081 & $1.53 \mathrm{E}-03$ & $1.8 \%$ \\
Xe-133m & 0.233 & $1.27 \mathrm{E}-03$ & $2.0 \%$ \\
Xe-135 & 0.250 & $1.20 \mathrm{E}-03$ & $2.0 \%$ \\
$\mathrm{I}-131$ & 0.364 & $9.55 \mathrm{E}-04$ & $2.3 \%$ \\
Xe-135m & 0.527 & $6.70 \mathrm{E}-04$ & $2.7 \%$ \\
Ar-41 & 1.294 & $3.19 \mathrm{E}-04$ & $4.0 \%$ \\
\hline
\end{tabular}

The release of radioactive gases from medical isotope production stack were real-time measured using the carborne survey equipment within the radius of $600 \mathrm{~m}$ from the stack. Meteorological data was measured over the same period. The result of real-time measurement of concentration released by the facilities were shown in Table 2 and 3. 
Table 2. Results of real-time measurements of ${ }^{131} \mathrm{I}$

\begin{tabular}{lc}
\hline Measurement Time & Concentration $(\mathbf{B q} / \mathbf{m} 3)$ \\
\hline 09:30 PM & 0.802 \\
10:00 PM & 0.629 \\
10:30 PM & 1.772 \\
11:00 PM & 2.021 \\
12:00 PM & 2.468 \\
01:00 AM & 2.805 \\
02:00 AM & 2.861 \\
03:00 AM & 2.828 \\
04:00 AM & 3.442 \\
05:00 AM & 3.231 \\
06:00 AM & 2.754 \\
07:00 AM & 1.163 \\
\hline
\end{tabular}

As can be seen in Table 2 and 3 that ${ }^{131}$ I and ${ }^{41} \mathrm{Ar}$ were detected by the developed carborne survey equipment succesfully. In comparison with ${ }^{131} \mathrm{I}$, the concentration of ${ }^{41} \mathrm{Ar}$ was relatively higher than that of ${ }^{131} \mathrm{I}$. Figure 9 shows one of gamma energy spectrum collected by using $\mathrm{NaI}(\mathrm{Tl})$ detector of carborne survey equipment during real-time measurement.

Table 3. Results of real-time measurements of ${ }^{41} \mathrm{Ar}$

\begin{tabular}{lc}
\hline Measurement Time & Concentration $(\mathbf{B q} / \mathbf{m 3})$ \\
\hline 05:16 PM & 5.572 \\
06:20 PM & 2.555 \\
07:20 PM & 5.526 \\
08:20 PM & 12.360 \\
09:20 PM & 18.471 \\
10:20 PM & 11.591 \\
11:20 PM & 11.190 \\
00:20 AM & 10.313 \\
01:20 AM & 15.285 \\
02:20 AM & 13.468 \\
03:20 AM & 16.793 \\
04:20 AM & 10.559 \\
05:20 AM & 32.109 \\
06:20 AM & 29.538 \\
$07: 20 \mathrm{AM}$ & 59.954 \\
\hline
\end{tabular}

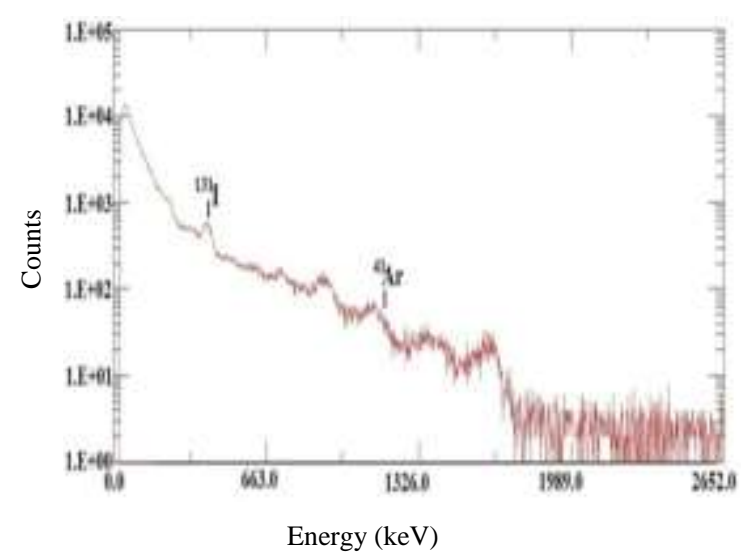

Fig. 9. $\mathrm{NaI}(\mathrm{Tl})$ gamma energy spectrum.

\section{CONCLUSION}

A carborne survey equipment has been designed and assembled for nuclear and radiological emergencies and normal condition. The performance of the mobile system has been tested for real-time measurements of the radioactive gases released from medical isotope production stack. There were two radioactive gases detected in this work such as ${ }^{131} \mathrm{I}$ and ${ }^{41} \mathrm{Ar}$. Thus this carborne survey equipment is capable of detecting and identifying a wide range of radioactive material while either at rest or traveling. This indicates that the mobile equipment is an effective tool for characterizing the impact of radioactive deposition in the environment.

\section{ACKNOWLEDGMENT}

The authors acknowledge the National Nuclear Energy Acency (BATAN) for the financial support throughout this work. The authors also gratefully acknowledge all staff of the Environmental Safety group for their technical assistance.

\section{REFERENCES}

1. T. Honkamaa, H. Toivonen and M. Nikkinen, Monitoring of Airborne Contamination Using Mobile Equipment, in: STUK-A Report, Finland (1996) 11.

2. M. Tanigaki, R. Okumura, K. Takamiya et al., Nucl. Instrum. Methods Phys. Res. A 726 (2013) 162.

3. S. Tsuda, T. Yoshida, M. Tsutsumi et al., J. Environ. Radioact. 139 (2015) 260.

4. M. Andoh, Y. Nakahara, S. Tsuda et al., J. Environ. Radioact. 139 (2015) 266.

5. K. Saito and Y. Onda, J. Environ. Radioact. 139 (2015) 240.

6. S. Kobayashi, T. Shinomiya, H. Kitamura et al., J. Environ. Radioact. 139 (2015) 281.

7. Anonymous, Guidelines for Radioelement Mapping Using Gamma Ray Spectrometry Data, IAEA, IAEA-TECDOC-1363 (2003).

8. Anonymous, Preparedness and Response for a Nuclear or Radiological Emergency, Safety Standards Series No. GS-R-2, IAEA (2002).

9. Anonymous, Method for Developing Arrangements for Response to a Nuclear or 
Radiological Emergency, EPR-METHOD, IAEA (2003) 34.

10. M.A. Smethurst, J.O. Mogaard and J. Koziel, A mobile Gamma Ray Spectrometer System for Nuclear Hazard Mapping, in: Gammalog v.3.0, NGU Report no. 2005.026, Geological Survey of Norway, Norway (2005) 5.

11. H.K. Aage, U. Korsbech, K. Bargholz et al., Appl. Radiat. and Isot. 64 (2006) 948.

12. P. Kock, Orphan Source Detection in Mobile Gamma-ray Spectrometry, Ph.D. Thesis, Lund University (2012).

13. S.W. Kwak, S.S. Chang and H.S. Yoo, J. Nucl. Sci. and Tech. 1 (2011) 252.

14. C.M. Salgado, L.E.B. Brandão, R. Schirru et al., Nucl. Energy 59 (2012) 19.

15. S.H. Byun, W.V. Prestwich, K. Chin et al., Nucl. Instrum. Methods Phys. Res. A535 (2004) 674.

16. Anonymous, MCNP-A General Monte Carlo $N$-Particle Transport Code, Version 5, Vol. 1, in: Overview and Theory, LA-UR-03-1987, Los Alamos National Laboratory, Los Alamos, New Mexico (2003) 108.

17. Anonymous, MCNP-A General Monte Carlo N-Particle Transport Code, Version 5. Vol. II, in: User's Guide, LA-UR-03-1987, Los Alamos National Laboratory, Los Alamos, New Mexico (2003) 1 .

18. Ed. Korpach, P. Mekarski and R.K. Ungar, Radiat. Prot. Dosimetry 160 (2014) 277.

19. I. Lowes, T. Parker, A. Whittall et al., Radioprotection 37 (2002) 453.

20. R.L. Grasty, B.R.B, Walters, J. Hovgaard et al., Radiat. Prot. Dosimetry 94 (2001) 309. 